\title{
High Mobility SiGe/Si n-Type Structures and Field Effect Transistors on Sapphire Substrates
}

\author{
Samuel A. Alterovitz ${ }^{1}$, George E. Ponchak ${ }^{1}$, Carl H. Mueller ${ }^{2}$, and Edward T. Croke ${ }^{3}$ \\ 1. NASA Glenn Research Center, 21000 Brookpark Rd., Cleveland, OH 44135; Tel: 216-433-3517; email \\ Samuel.A.Alterovitz@grc.nasa.gov \\ 2. Analex Corporation, Cleveland, $\mathrm{OH}$ \\ 3. HRL Laboratories LLC, Malibu, CA
}

\begin{abstract}
SiGe/Si n-type modulation doped field effect transistors (MODFETs) fabricated on sapphire substrates have been characterized at microwave frequencies for the first time. The highest measured room temperature electron mobility is $1380 \mathrm{~cm}^{2} / \mathrm{V}$-sec at a carrier density of $1.8 \times 10^{12} \mathrm{~cm}^{-2}$ for a MODFET structure, and $900 \mathrm{~cm}^{2} / \mathrm{V}$-sec at a carrier density of $1.3 \times 10^{12} \mathrm{~cm}^{-2}$ for a phosphorus ion implanted sample. A two finger, $2 \times 200$ micron gate n-MODFET has a peak transconductance of $37 \mathrm{mS} / \mathrm{mm}$ at a drain to source voltage of $2.5 \mathrm{~V}$ and a transducer gain of $6.4 \mathrm{~dB}$ at $1 \mathrm{GHz}$.
\end{abstract}

Index Terms-SiGe, MODFET, sapphire.

\section{INTRODUCTION}

CiGe /Si n-type modulation doped field effect transistors $N_{\text {(MODFETs) on sapphire have the potential to integrate }}$ high speed $\mathrm{Si}$ technology with high quality microwave passives on the same substrate. However, while p-type MODFETs on sapphire have been reported, there are no publications on n-MODFETs on sapphire to our knowledge. All Si based devices on sapphire use silicon-on-sapphire (SOS) as a starting substrate, which has the Si layer in compressive strain. While this aids the fabrication of $\mathrm{p}$ MODFETs, which have compressive strained SiGe channels, it complicates the fabrication of n-MODFETs, which require tensile strained Si channels. Here we report, for the first time, a microwave $\mathrm{SiGe} / \mathrm{Si} \mathrm{n}$-MODFET device on a sapphire substrate.

\section{SUMMARY}

High mobility n-type SiGe/Si field effect transistors (FET) transistor structures have been fabricated by MBE on sapphire substrates using strained $100 \AA$ thick silicon channels. The strained $\mathrm{Si}$ channels are sandwiched between $\mathrm{Si}_{0.7} \mathrm{Ge}_{0.3}$ layers, which, in turn, are deposited on $\mathrm{Si}_{0.7} \mathrm{Ge}_{0.3}$ virtual substrates and graded SiGe buffer layers (Fig. 1). The electrons in the strained Si channels are obtained using two methods: modulation doping of the top $\mathrm{Si}_{0.7} \mathrm{Ge}_{0.3}$ layer using a delta-doped $\mathrm{Sb}$ technique (thereafter called the n-MODFET structure), and phosphorous ion implantation followed by post-annealing. The highest room temperature electron mobilities measured are $1380 \mathrm{~cm}^{2} / \mathrm{V}-\mathrm{sec}$ at a carrier density of $1.8 \times 10^{12} \mathrm{~cm}^{-2}$ for the n-MODFET structure, and 900 $\mathrm{cm}^{2} / \mathrm{V}$-sec at a carrier density of $1.3 \times 10^{12} \mathrm{~cm}^{-2}$ for a phosphorous ion implanted sample (Fig. 2). A systematic study of the ion implanted samples showed that the electron concentration appears to be the key factor that determines mobility, with the highest mobility observed for electron densities in the $1-2 \times 10^{12} \mathrm{~cm}^{-2}$ range (Fig. 2). For the nMODFET structure, mobility above 13,000 is measured at liquid He temperatures accompanied by Shubnikov de-Haas oscillations, showing the existence of a 2DEG and excellent confinement of the electrons (Fig. 3 and Table 1).

n-MODFETs with gate dimensions of $2 \times 200,3 \times 200$, and $5 \times 200 \mu \mathrm{m}$ were fabricated on the $\mathrm{Sb}$ delta-doped material. The IV characteristics of the $2 \times 200 \mu \mathrm{m}$ gate transistor are shown in Figs. 4 and 5. An $I_{D s}$ of $9 \mathrm{~mA}$ is obtained by operating the transistor in an enhancement mode (positive $V_{G S}$ ) and the maximum transconductance $\left(g_{m}\right)$ is 37 $\mathrm{mS} / \mathrm{mm}$ at a $V_{D S}$ of $2.5 \mathrm{~V}$. The transducer gain $\left(\mathrm{G}_{t}\right)$ is $4.4 \mathrm{~dB}$ at $800 \mathrm{MHz}$ and $6.4 \mathrm{~dB}$ at $1 \mathrm{GHz}$ for a $\mathrm{V}_{\mathrm{DS}}$ of $2.5 \mathrm{~V}$ and $\mathrm{V}_{\mathrm{GS}}=-0.4 \mathrm{~V}$.

\section{CONCLUSION}

n-MODFETs fabricated on r-plane sapphire substrates have demonstrated microwave frequency characteristics for the first time, but further development is required to improve the Schottky contacts and increase the carrier density.

\section{REFERENCES}

[1] C. H. Mueller, E. T Croke and S. A. Alterovitz, "High electron mobility $\mathrm{SiGe} / \mathrm{Si}$ n-MODFET structures on sapphire substrates", Elec. Lett. 39 (18), p. 1353-1354 (2003). 


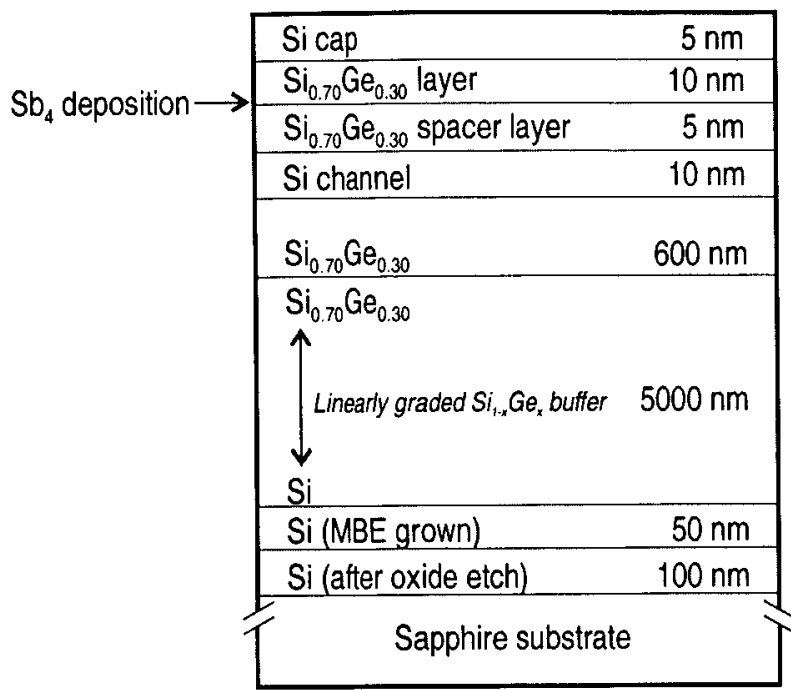

Figure 1: Schematic diagram of buffer layer, virtual substrate, and channel of the n-MODFET SiGe/Si transistor on sapphire substrate.

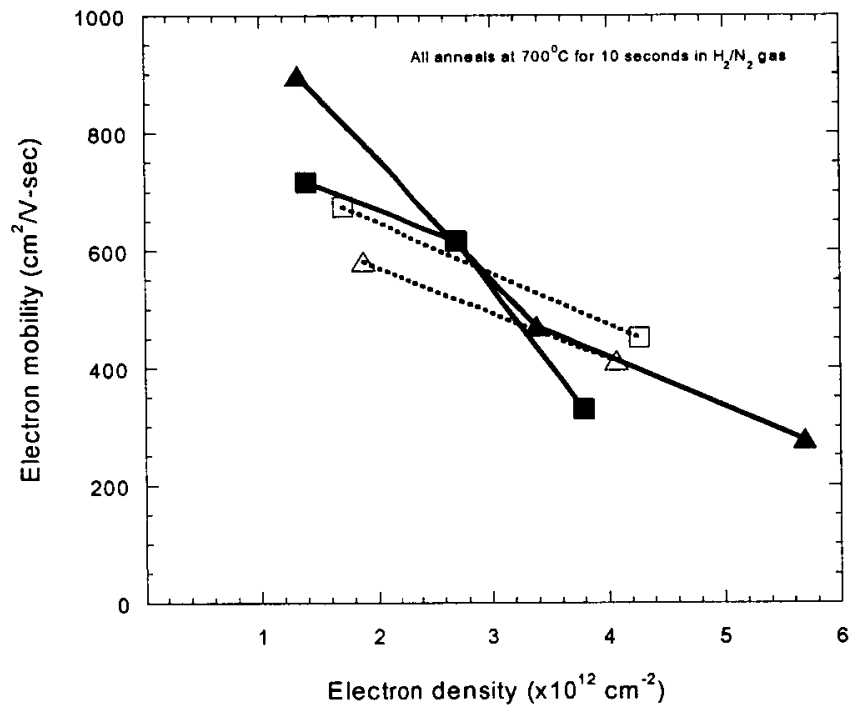

Figure 2: Room temperature mobility versus electron density for the high mobility phosphorous ion implanted $\mathrm{SiGe/Si}$ structures with different buffers and surface-to-channel distances.

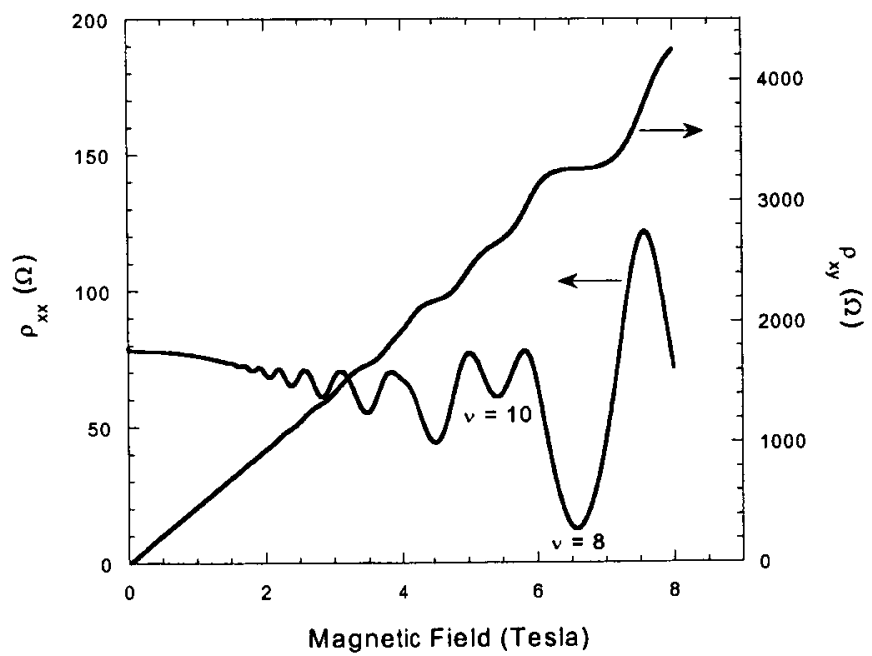

Figure 3: Longitudinal $\left(\rho_{x x}\right)$ and Hall $\left(\rho_{x y}\right)$ resistivity versus magnetic field for the $\mathrm{n}$-MODFET $\mathrm{SiGe} / \mathrm{Si}$ structures. Data taken at $0.25 \mathrm{~K}$.

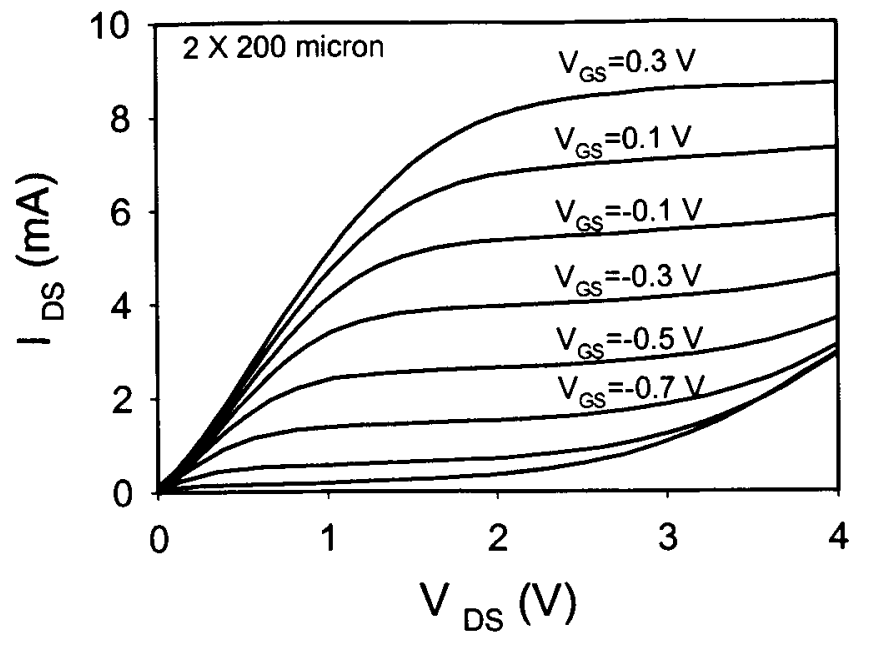

Figure 4: Measured IV characteristics of $2 \times 200$ micron n-MODFET.

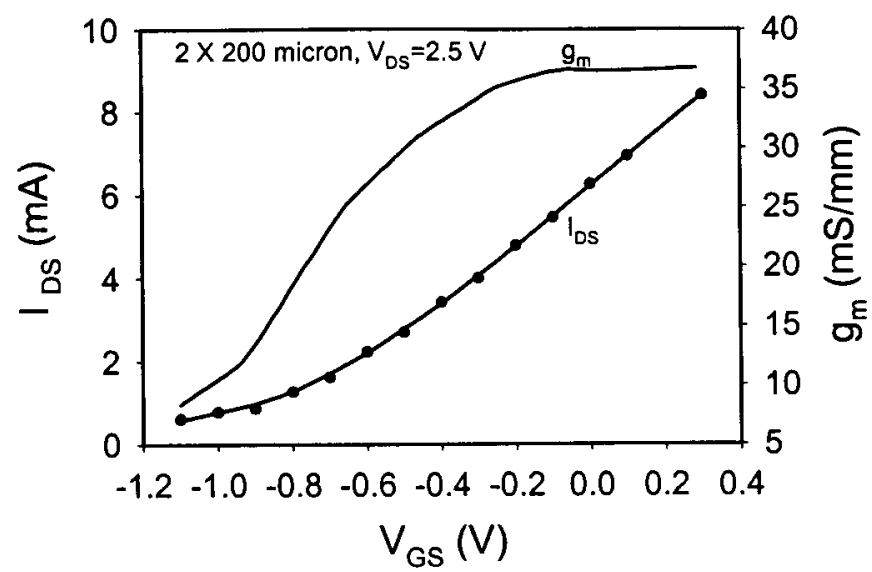

Figure 5: Measured transconductance of $2 \times 200$ micron n-MODFET.

Table 1: Summary of electron mobility, electron concentration, and sheet resistance at 0.25 and $300 \mathrm{~K}$ for $\mathrm{n}$-MODFET SiGe/Si transistors.

\begin{tabular}{|c|c|c|c|}
\hline $\begin{array}{c}\text { Temperature } \\
(\mathrm{K})\end{array}$ & $\begin{array}{c}\text { Electron } \\
\text { Concentration } \\
\left(\mathrm{x} 10^{12} \mathrm{~cm}^{-2}\right)\end{array}$ & $\begin{array}{c}\text { Hall } \\
\text { Mobility } \\
\left(\mathrm{cm}^{2} / \mathrm{V}-\mathrm{sec}\right)\end{array}$ & $\begin{array}{c}\text { Sheet } \\
\text { Resistance } \\
(\Omega / \mathrm{sq} .)\end{array}$ \\
\hline 300 & 1.6 & 1271 & 3073 \\
\hline 0.25 & 1.33 & 13,313 & 352 \\
\hline
\end{tabular}

